\title{
ORGANIZAÇÕES INTERNACIONAIS NÃO-ESTATAIS, DESENVOLVIMENTO ECONÔMICO E TRANSPLANTES JURÍDICOS: EM DEFESA DO DESCOLONIALISMO NA AMÉRICA LATINA
}

\author{
NON-STATE INTERNATIONAL ORGANIZATIONS, ECONOMIC \\ DEVELOPMENT AND LEGAL TRANSPLANTS: IN DEFENSE OF \\ LATIN AMERICAN DECOLONIALISM
}

ReSUMO: A compreensão dos problemas do desenvolvimento econômico na América Latina, sob uma matriz regional e uma lógica metrópole-colônia, suscita e perpassa algumas considerações relacionais que envolvem as ideias império, leis de império, Estado de Direito, Teoria dos Transplantes Legais (legal transplants) e a Escola direito e desenvolvimento (law and development). A questão que se coloca é: A questão que se coloca é: Como estabelecer e conceber um modelo de desenvolvimento econômico emancipatório (descolonial), a partir das necessidades e desigualdades próprios da região, frente a multiplicidade de institutos e instrumentos de ordenação-manipulação de poder econômico, notadamente frente as condicionalidades e condicionantes dos Organismos Internacionais Não-Estatais (Banco mundial)? Este é o objeto central do artigo. A pesquisa é eminentemente documental, tendo como referencial teórico o conceito de teoria dos transplantes legais, "law and development" e a matriz desenvolvimentista descolonial, desenvolvidos pelos Professores Watson, Mattei, Frankenberg, Lopez-Medina e Mignolo. O método de investigação científica, ou seja, analítico substancial. $\mathrm{O}$ artigo aborda as teorias de comparação constitucional, em uma perspectiva dinâmica dos "fluxos jurídicos", próprio do contexto normativo globalizante, utilizando-se fundamentos doutrinários da Teoria dos legal transplants contextualizados histórica e culturalmente com a realidade latino-americana, no propósito de consagrar identidade e fundamento legitimador do desenvolvimento

${ }_{1}$ Doutorando em Direito Constitucional pela Universidade de Fortaleza UNIFOR/PPGD. Professor universitário - FANOR-DeVry Brasil. Procurador Federal - AGU. E-mail: rguilhermeleitao@hotmail.com 
econômico. Por fim, demonstra-se que a internacionalização de modelos de desenvolvimento econômico consagra reformas políticos-institucionais e jurídicos, engendradas por Organismos Internacionais Não-Estatais.

Palavras-Chave: Organismos internacionais não-estatais; Transplantes Legais; Desenvolvimento econômico; Descolonialismo; América-latina.

ABSTRACT: The understanding of the problems of economic development in Latin America, under a regional matrix and a metropolis-colony logic, raises and perpasses some relational considerations involving empire ideas, empire laws, the rule of law, legal transplant theory transplants) and the School law and development. The question that arises is: How can we establish and devise a model of emancipatory (decolonial) economic development, based on the region's own needs and inequalities, in face of the multiplicity of institutes and instruments of ordering-manipulation of economic power, notably in view of the conditionalities and constraints of non-state international organizations (World Bank)? This is the central object of the article. The research is eminently documentary, having as theoretical reference the concept of legal transplantation theory, "law and development" and the decolonial developmental matrix, developed by Professors Watson, Mattei, Frankenberg, Lopez-Medina and Mignolo. The method of scientific investigation, that is, analytical substantial. The article deals with theories of constitutional comparison, in a dynamic perspective of "juridical flows", typical of the globalizing normative context, using doctrinal foundations of the theory of legal transplants contextualized historically and culturally with Latin American reality, in the purpose of consecrating identity and legitimizing foundation of economic development. Finally, it is shown that the internationalization of models of economic development consecrates political-institutional and legal reforms, engendered by Non-State International Organizations.

KEYWORDS: Non-State international organizations; Legal transplants; Economic development; Decolonialism; Latin America.

\section{INTRODUÇÃO}

A compreensão dos problemas do desenvolvimento econômico na América Latina, sob uma matriz regional, suscita e perpassa algumas considerações relacionais que envolvem as ideias de império, leis de império, Estado de Direito, Teoria dos Transplantes Legais (legal transplants) e a Escola direito e desenvolvimento (law and development). Tal lógica, que vincula e aproxima o direito internacional econômico 
(Organismos Internacionais Não-Estatais) à herança colonial, e consagra os modelos político-institucionais e econômico-sociais de desenvolvimento econômico na região, dá contornos e norteamentos nos ordenamentos jurídicos dos países latinos americanos. A questão que se coloca é: Como estabelecer e conceber um modelo de desenvolvimento econômico emancipatório (descolonial), a partir das necessidades e desigualdades próprios da região, frente a multiplicidade de institutos e instrumentos de ordenação-manipulação de poder econômico, notadamente frente as condicionalidades e condicionantes dos Organismos Internacionais Não-Estatais (Banco mundial)? Este é o objeto central do artigo.

Para tanto, o desenvolvimento econômico há de ser concebido como um sistema institucional e jurídico complexo, isto é, como sistema no qual a interação entre atores e processos, numa relação espaço-temporal, que apresenta diversidade e dinâmica próprios, e, portanto, com natureza jurídica-normativa incompatível com a matriz desenvolvimentista propostas pelo Banco Mundial nas cartilhas do World Bank legal report.

Com efeito, há de ser feita uma análise dos fluxos normativos dos elementos marcantes dos arranjos institucionais e normativos que caracterizam e condicionam os modelos de desenvolvimento econômico, consagrados e patrocinados por organismos internacionais não-estatais. Dispõe-se a enfrentar o tema das ingerências impostas por Organismos Internacionais, com o fim de promover, financiar, implementar e reformar o arcabouço jurídico e político-institucional propício ao desenvolvimento econômico na América Latina.

\section{TEORIA DOS TRANSPLANTES LEGAIS: JURISTAS COLONIZADOS?}

O artigo aborda as teorias de comparação jurídica, numa perspectiva dinâmica dos "fluxos jurídicos", próprio do contexto normativo globalizante, utilizando-se fundamentos doutrinários da Teoria dos transplantes legais, contextualizados histórica e culturalmente com a realidade latino-americana, no propósito de consagrar identidade e fundamento legitimador da matriz desenvolvimentista da América Latina.

Por fluxos jurídicos concebem-se interações comunicativas que ocorrem entre os operadores do direito de diversos ordenamentos e racionalidades jurídicas. Esta dinâmica normativa produz imitações, migrações de ideias constitucionais, empréstimos constitucionais entre várias ordens jurídicas. Toda a dinâmica e fluxo de formantes e fontes jurídicas revela grande similitude entre a realidade experimentada entre Metrópole-Colônia nos séculos XV e XVI, diante da realidade vivida no ocaso do século XX e início do século presente.

Com efeito, a historicidade e as experiências imperiais da américa latina consagraram e imprimiram as políticas, o ensino e as práticas do direito na região, impondo e condicionando o padrão eurocêntrico das metrópoles (Espanha, Portugal, França e Inglaterra). Outrossim, é imperioso consignar a narrativa imperial, com o transcorrer dos séculos, alterou-se em forma, mas não na essência. Em sentido conforme, Sara Araújo (2015, p. 26-46), Investigadora do Centro de Estudos Sociais da 
Universidade de Coimbra, em artigo "Desafiando a Colonialidade: A Ecologia de justiças Como instrumento Da descolonização Jurídica" constata que:

O colonialismo europeu não foi apenas um projeto econômico e político, que envolveu a exploração de recursos e a dominação política de povos, tendo terminado com as descolonizações formais. Deixou um legado de injustiça, assente na colonialidade do poder (Quijano, 2009), alimentado por uma estrutura colonizadora responsável pela marginalização de sociedades, culturas e seres humanos (Mudimbe, 1988). Se as relações políticas mudaram com o fim político dos impérios coloniais, as narrativas hegemónicas sobre as quais assentou a alegada superioridade dos países do Norte não foram decisivamente postas em causa e são constitutivas do projeto da modernidade.

Portanto, o colonialismo e o movimento descolonial guardam consigo operacionalidades e similitudes de dominação política dos povos que demonstram o caráter imperial, veiculados por leis imperiais (e posteriormente do imperialismo póscolonial, neo-imperial) imbricadas com narrativas históricas de gestão e governos, intervenções políticas, econômicas de direito internacional e do direito nacional ou doméstico.

Walter Mignolo (2008, p. 239-252) defende o contexto histórico de construção e conformação da América Latina guardando imbricada relação com o passado imperial da colonização. No trabalho "Novas reflexões sobre "Ideia da América Latina": a direita, a esquerda e a opção descolonial". O autor assevera que:

O Novo Mundo e a América são invenções européia-cristãs, cujos agentes foram as monarquias e, em seguida, os estados-nacionais do Atlântico. A formação histórica do mundo moderno-colonial resultou das ações e das narrativas produzidas basicamente em quatro das seis línguas modernas imperiais: português, castelhano, francês e inglês. (...) Por tudo isso, é necessário atender ao nível ontológico da ideia da América Latina, e prestar atenção além do mais ao nível ôntico. Isto é, não aceitar a América Latina como uma coisa natural e contar histórias do que lá acontece, esquecendo que tudo que lá ocorre tem sua razão de ser na história imperial-colonial de como a América Latina foi constituída.

Nesta ambiência de Metrópole-colônia, as leis imperiais de outrora, guardam aproximada relação com as reformas político-institucionais e jurídicas impostas e condicionadas por organismos internacionais não-governamentais, engendradas por nações desenvolvidas. O elemento de descrímen, há de ser ressaltado, no caso da América Latina, nos casos de fluxos normativos é a existência de transferências voluntárias e outras frequentemente violentas, resultantes da teorização da teoria da lei imperial consagradora do processo geral de americanização do pensamento jurídico. 
Como consequência do fenômeno, forma-se uma camada dominante dos sistemas jurídicos em todo o mundo e é produzida, no interesse do capital internacional, por uma variedade de instituições públicas e privadas, e compartilhada com uma lacuna de legitimidade.

Neste contexto, o referido modelo legislativo é moldado por um processo espetacular de contundência, para fins de dominação hegemônica, estabelecendo e subordinando arranjos legais locais de todo o mundo, reproduzidos em escala mundial o mesmo fenômeno do dualismo legal que até agora tem como característica o direito internacional dos países em desenvolvimento.

A internacionalização de modelos políticos-institucionais e jurídicos, com baixa densidade democrática, perpassa fronteiras, macula o Estado Nacional e corrompe a Soberania Política, pautando abalos e corrosões nos sistemas políticos que afetam o paradigma normativo tanto a nível de sistemas internos, como na ordem internacional e supranacional. Reforçando, Ferrajoli (2005, p. 222) constata que "o Ocidente exportou durante o século passado um modelo já em estado de crise nacional, e, em conjunto, a ilusão de que havia garantias suficientes para autodeterminação e independência."

Ocorre, no entanto, que tal modelo pressupõe um processo decisório antecipado tomadas de decisões no centro do mundo: isto é, das políticas decididas "democraticamente" pelas maiorias ricas e influentes de um número restrito de potências ocidentais que controlam Instituições internacionais e o direito internacional econômico delas resultantes.

Inicia-se abordando o constitucionalismo latino-americano, revelando-se um constitucionalismo com institutos, instituições e dinâmicas próprios. Para tanto, primeiramente, realiza-se uma análise bibliográfica de títulos nacionais e estrangeiros, notadamente estes últimos, dando-se ênfase à doutrina de centro acadêmicos com realidade social, cultural e econômica que guarde similitude com a realidade brasileira após-1988.

Outrossim, é estudado e compilado bancos de dados institucionais, nacionais e de atores e agentes internacionais e multilaterais, notadamente as agências do Banco mundial. Por fim, far-se-á uma análise crítico-construtiva e histórica das ingerências e condicionamentos impostos por Organismos Internacionais Não-Estatais, de natureza econômica e financeira, notadamente as engendrados pelo Banco Mundial, com o fim de promover, financiar, implementar e reformar o arcabouço jurídico-constitucional e político-institucional latino-americano, veiculando como propósito o enfrentamento do subdesenvolvimento econômico, bem como, perscrutar as consequências normativas deste fenômeno frente o Estado de Direito.

\section{CONSTITUCIONALISMO LATINO-AMERICANO: HÁ UM IUS CONSTITUTIONALE COMMUNE NA AMERICA LATINA?}

O equacionamento destas questões denota as premissas do trabalho, no sentido de se buscar de que forma, com qual engenharia político-institucional e normativa, os países pertencentes à geopolítica latino-americana salvaguardam os seus respectivos 
mercados internos das ingerências e condicionantes econômico-financeiras dos atores internacionais não-Estatais.

Inicialmente, deve-se enfrentar aos questionamentos: há um constitucionalismo de matriz latino-americana? Se há, há um direito internacional de matriz latinoamericana? $\mathrm{O}$ que há de originalidade na Região que revela um direito internacional de matriz latino-americana com institutos, instituições e dinâmicas próprios a ponto de adjetiva-los? A resposta somente pode ser positiva, para o primeiro questionamento. Já para a segunda pergunta, na América Latina, o Imperialismo e colonialismo presente na Região conformou um modelo de direito internacional colonial, próprio dos séculos XIV e XV. E a razão surge do cotejo entre o constitucionalismo liberal clássico e o constitucionalismo latino-americano. Gisele Cittadino, ao imprimir a juridicidade estatal (monismo), consagra o modelo do constitucionalismo clássico:

\begin{abstract}
O constitucionalismo clássico, de matriz liberal, associa o ordenamento normativo a defesa da autonomia privada dos sujeitos não apenas porque ela fixa os limites dos mecanismos da violência monopolizada pelo Estado, mas também porque institucionaliza os processos de tomada de decisão, de elaboração legislativa e da aplicação da lei aos casos concretos. Não é por outra razão que os ordenamentos normativos costumam ser analisados como sistemas jurídicos vinculados aos Estados, ou, em outras palavras, o modelo dominante de juridicidade é o direito estatal. (CITTADINO, 2017, p. 01)
\end{abstract}

Com efeito, o constitucionalismo contemporâneo, próprio do ocaso do século XX e início do século XXI, e sob a égide do fenômeno da mundialização da economia de mercados, da política, da governança global padece de novas engenharias normativas e institucionais na consecução de ordenar juridicamente tal fenômeno.

Acresça-se aos efeitos da mundialização, na matriz constitucional contemporânea, as condicionantes da fragmentação e a privatização. Tais problemas suscitam a constitucionalização de regimes regulatórios transnacionais e supranacionais bem como a emergência de novas formas de colisão entre regimes normativos (latu sensu), que alteram os mecanismos de funcionamento e exercício do poder estatal. Nas formas emergentes de administração do direito e do poder regulatório em nível transnacional e supranacional (HOLMES, 2014, p. 1137), as Políticas Públicas de desenvolvimento econômico padecem de interferências determinantes e condicionantes por atores internacionais não-estatais.

Neste contexto de mundialização de mercados, fragmentação de racionalidades normativas e privatização de atores não-estatais globais, que o constitucionalismo contemporâneo busca compatibilizar sua matriz liberal e monista estatal originária com o contexto histórico, político, econômico e jurídico constitucional atual.

A solução de compatibilidade entre o constitucionalismo clássico, de matriz liberal, e o constitucionalismo contemporâneo possibilita a emergência de ordens plurais para além do Estado nacional, veiculadas por termos como "pluralismo jurídico" (TEUBNER, 1996, p .04). Esta pluralidade de racionalidades normativas possibilita ao 
constitucionalismo latino-americano se insurgir do processo histórico de colonização, desconstruindo-se e buscando alternativas emancipatórias. Neste contexto, pertinente a observação de Valéria Ribas do Nascimento, Evilhane Jum Martins e Micheli Capuano Irigaray:

O Constitucionalismo Contemporâneo na América Latina vem surgindo enquanto mudança de paradigma que visa implementar parâmetros de descolonização e reaproximação das características originárias dos povos latinos em sua essência, permeando pela representação do Estado Plurinacional, para o surgimento de um novo constitucionalismo latino-americano. Esse novo modelo constitucional latino-americano é fruto de reivindicações de comunidades locais, que em todo contexto histórico existente até a atualidade, manteve sua identidade sociocultural própria excluída do cenário global. (NASCIMENTO; MARTINS; IRIGARAY, 2016, p. 544)

O constitucionalismo latino-americano surge como consectário do Estado Plurinacional, fruto das vicissitudes históricas, políticas, econômicas e jurídicoconstitucionais. E mais, surge uma Ius Constitutionale Commune na América Latina (ICCAL), veiculando uma abordagem regional-local sobre o constitucionalismo transformador (VON BOGDANDY, 2015, p. 03). A razão para o direito constitucional comum latino-americano se revela nos seguintes termos:

Esse enfoque se assenta na inquietante experiência adquirida com as inaceitáveis condições de vida existentes, e aponta para a transformação da realidade política e social da América Latina, por meio do fortalecimento da democracia, do Estado de direito e dos direitos humanos. Os problemas comuns aos países latino-americanos, tais como a exclusão de amplos setores da sociedade, bem como a deficiente normatividade dos direitos, são temas centrais dessa abordagem. O ICCAL não aposta somente na integração funcional da região, mas sim em um constitucionalismo regional dos direitos com garantias supranacionais. Como resultado deste, os representantes do ICCAL reconhecem a tão estreita relação que existe entre os direitos constitucional, internacional e comparado. A abertura dos ordenamentos jurídicos nacionais de numerosos países latinoamericanos, com o direito internacional e, em particular, com o sistema interamericano de proteção dos direitos humanos, é de particular importância e constitui o núcleo normativo do ICCAL. (VON BOGDANDY, 2015, p. 04)

Superados os três questionamentos iniciais, quais sejam: 1) há um direito internacional latino-americano? 2) há originalidade neste direito internacional com institutos, instituições e dinâmicas próprios a ponto de adjetiva-los? 3) Há uma 
homogeneidade, sem que haja necessariamente identidade, na realidade jurídicoconstitucional dos países integrantes da América Latina?; o presente artigo tem por fim enfrentar e dimensionar as formas de ingerências dos organismos internacionais não-estatais nas políticas de desenvolvimento econômico nacionais, frente o Ius Constitutionale Commune na América Latina (ICCAL).

Para tanto, e com a utilização das teorias dos legal transplants e da law and development, são descritas políticas de desenvolvimento econômico engendradas pelo Banco Mundial2², bem como o nível de inserção e ingerência destas nas políticas nacionais de desenvolvimento econômico.

\section{DESENVOLVIMENTO ECONÔMICO E A COMPREENSÃO REFERENCIAL}

\section{LEGAL TRANSPLANTS E ESCOLA DA LAW AND DEVELOPMENT}

A O presente tópico do artigo visa ao abordar as teorias do direito comparado, na América Latina, numa perspectiva dinâmica dos "fluxos jurídicos", em um contexto normativo globalizante, de matiz desenvolvimentista. Para tanto, utiliza-se fundamentos doutrinários da Teoria dos legal transplants (WATSON, 1993, p. 17; FRANKENBERG, 2007, p. 173; MATTEI, 1994, p. 06; LOPEZ-MEDINA, 2015, p. 137) contextualizando histórica e culturalmente, no propósito de consagrar identidade e fundamento legitimador ao constitucionalismo latino-americano.

Lucio Pegoraro (2014, p. 33) em ensaio Trasplantes, injertos, diálogos: Jurisprudencia y doctrina frente a los retos del derecho comparado adverte para a pluralidade de nomenclaturas utilizadas para se referir ao mesmo fenômeno jurídico: "trasplantes", "legal borrowing", "migracion" "turismo legal" "cross-fertilizacion" e "diálogos" com variantes devidas aos sistemas jurídicos que originam.

Caracterizados e contextualizados os fluxos normativos, notadamente pela teoria dos legal transplants, o texto lança luzes nas interferências e condicionantes dos atores internacionais não-estatais, de natureza econômica e financeira, notadamente as engendrados pelo Banco Mundial, com o fim de promover, financiar, implementar e reformar o arcabouço jurídico-constitucional e político-institucional brasileiro, e da América Latina como um todo, veiculando como propósito o enfrentamento do subdesenvolvimento econômico, bem como, perscrutar as consequências normativas deste fenômeno frente os Estado nacionais.

Com efeito, as múltiplas significações dos termos teoria dos legal transplants e Escola da Law and development nos apresenta útil para uma mais apropriada apreensão do tema. Observe-se que o debate acadêmico das temáticas tem suscitado no estudo das ciências jurídicas metodologias sobremaneira alargadas e, diante da multiplicidade de enfoques, necessárias são alguns esclarecimentos conceituais. Para

\footnotetext{
${ }^{2}$ A Comissão Econômica para a América Latina (CEPAL) foi estabelecida pela resolução 106 (VI) do Conselho Econômico e Social, de 25 de fevereiro de 1948, e começou a funcionar nesse mesmo ano. Mediante a resolução 1984/67, de 27 de julho de 1984, o Conselho decidiu que a Comissão passaria a se chamar Comissão Econômica para a América Latina e o Caribe.
} 
tanto, maior ênfase será dada às significações com reflexos na ordem jurídicoconstitucional.

Inicia-se pela da teoria dos legal transplants. A dimensão conceitual do fenômeno jurídico da transnacionalidade do direito, e por via de consequência, de seus efeitos, vem sendo objeto de estudo multidisciplinar, que, por muitas vezes, acertadamente, interagem e concebem múltiplas teorias acerca da sua compreensão. Marcelo Neves na obra "Transnacionalidade do direito: novas perspectivas dos conflitos entre ordens jurídicas", aponta para a dificuldade ciência jurídica tradicional conceber o fenômeno da transnacionalidade do direito frente a prescindibilidade estatal, vez que o EstadoNação habita o cerne da doutrina do direito internacional. Neste contexto, Neves (2010, p. 09) assevera:

\begin{abstract}
A emergência de ordens jurídicas transnacionais e supranacionais, em formas distintas do direito internacional público clássico é um fato incontestável que vem chamando a atenção e tornando-se cada vez objeto do interesse de estudos não apenas de juristas, mas também de economistas e cientista sociais em geral. O que intriga a "ciência" jurídica tradicional é a pretensão dessas novas ordens jurídicas de se afirmarem impreterivelmente, seja como ordem jurídica que prescindem do Estado ou como ordem jurídicas que prevalecem contra os Estados, pondo em cheque o próprio princípio da soberania estatal, viga mestra do direito internacional público clássico.
\end{abstract}

Em estudo acerca da relação existente em transnormatividade e cosmopolitísmo jurídico, Branco (2014) sintetiza a ideia de transnacionalidade do Direito como "fenômeno jurídico-axiológico que se consolida mediante a transcendência e a capilaridade de normas e regulamentos internacionais sobre o direito doméstico dos países".

Com efeito, o binômio transcendência-capilaridade (ou, para os fins do estudo, cartilha de reformas do Banco Mundial/legal transplants) é atributo das políticas econômicas engendradas pelo Grupo do Banco Mundial, notadamente na matriz neoinstitucionalista de desenvolvimento consagrada, que perpetra frequentes reformas político-institucionais, com arranjos jurídicos-processuais subjacentes. No cumprimento das metas das cartilhas do World Bank legal report. ${ }^{3}$

E qual é relação entre o exposto até aqui e o tema do presente trabalho? Essa relação pode ser instrumentalizada por meio da compreensão de que o conflito entre duas ordens - Nacional/Regional e transnacional (ou, ordem constitucional e Banco Mundial) - poderia ampliar ainda mais o suposto grau de colisão e irracionalidade na aplicação do direito (SILVA, 2009, p. 101). Isso porque teríamos dois níveis de sopesamento entre pelo menos dois modelos de direito constitucional.

\footnotetext{
3 Veja http://www.worldbank.org/en/events/2017/03/28/law-justice-and-development-week-2017. Acesso em 06 jun. 2017.
}

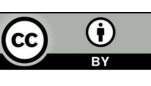


O constitucionalmente consagrado (constitucionalismo latino-americano), e por via de consequência, concebido sob um viés de historicidade, subjacente a direitos sociais advindos da redemocratização latino-americana e, de outra perspectiva, o transplantado de modelos de nações desenvolvidas, de natureza exógena, pois concebido por atores internacionais não- estatais e, construídos sob um arcabouço jurídico da common law.

Gunther Teubner (2012, p. 21) defende a tese do conflito das racionalidades na obra Constitutional Fragments: Societal Constitutionalism and Globalization. Para o autor, o antagonismo das lógicas jurídicas entre os diferentes subsistemas (a razão de natureza constitucional desenvolvimentista consagradas na Constituição Federal de 1988 diante do modelo do law and development concebido pelo Banco Mundial) e sua consequente colisão entre a racionalidade de um subsistema com as diferentes racionalidades que os vários atores têm de uma sociedade global (notadamente o Banco Mundial) e, ainda, conflitos de racionalidades de um subsistema com os próprios padrões racionais compreendidos como necessários para sua expansão tornam-se frequentes e contraproducentes. Marcelo Varella (2012, p. 104) em sentido conforme, corrobora:

Direito nacional e direito internacional ampliam seus elementos comuns. O direito constitucional é pressionado em função do aumento da governança internacional, que se torna cada vez mais efetiva, removendo barreiras centrais para alcançar os ordenamentos domésticos. Ambos, direito nacional e direito internacional, sofrem mudanças radicais. A clássica distinção entre a esfera doméstica e a internacional torna-se menos nítida, sobretudo em alguns temas e regiões.

Para que se possa estabelecer um juízo acerca dos dilemas e os desafios propostos pela emergência de ordens jurídicas transnacionais e supranacionais, no que se refere ao modelo desenvolvimentista latino-americano e o conflito não aparente com as políticas jurídico-institucionais, patrocinadas pelo Banco Mundial, há de se enfrentar questões centrais a saber: 1) Identificar qual a relação existente entre "rule of law" e a matriz desenvolvimentista do Banco Mundial e da Cepal; 2) Discutir de que maneira o modelo econômico de desenvolvimento constitucionalmente consagrado tem incorporado os relatórios de aconselhamento do Banco Mundial; 3) Examinar qual das concepções da Escola "Law and Development" a ser adotada, vislumbrando os atores internacionais e nacionais ativamente envolvidos; 4) Conceber a relação existente entre desenvolvimento econômico e arranjos jurídico e/ou institucionais, notadamente nos preceitos constitucionais consagrados nas constituições latino-americanas.

\section{COMMON LAW, RULE OF LAW E A MATRIZ DESENVOLVIMENTISTA DO BANCO MUNDIAL}

As instituições de direito internacional econômico, ou Organismos Internacionais Não-Estatais, concebem a ideia de desenvolvimento econômico atribuindo intrínseca relação com uma matriz institucional e de arranjos normativos concebidos no sistema

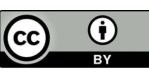


jurídico da common law e, portanto, discrepando das normatividades latinoamericanas, todas de natureza romano-germânica(civil law).

Neste diapasão, a Teoria dos transplantes jurídicos, consagrando os modelos globalizantes de capital e a matriz do rule of the law, veiculou e propagou o modelo de desenvolvimento econômico, financiado pelo Banco mundial, sob a condicionante de reformas institucionais, jurídicas e de gestão administrativa em toda América Latina. "É difícil imaginar uma outra expressão do discurso político anglo-americano, que seja melhor conhecida e prestigiada a nível global do que a rule of the law."

Parte do prestígio do engenho político-institucional fora consagrados, no entendimento de Mattei, em ensaio Emergency-Based Predatory Capitalism: The Rule of Law, Alternative Dispute Resolution, and Development pela experiência constitucional dos Estados Unidos da América do Norte, que:

Forneceram um impulso vital para o prestígio do Estado de direito. Especificamente, em The Federalist Papers (em particular, no Madison № 10 e de Hamilton № 23), o Estado de Direito foi concebido como a única maneira de garantir a estabilidade política numa sociedade caracterizada por desigualdades e em que ricos proprietários estavam em minoria e deviam ser defendido contra a maioria da população que não possui propriedade. O Estado de Direito, que era confiado aos tribunais, possuía a sabedoria de proteção jurídica da propriedade privada, essencial e permanente garantia institucional para os proprietários na ordem constitucional americana pós-revolucionária e destinada a ganhar a hegemonia em todo o mundo atual. (MATTEI, 2009, p. 92)

A internacionalização de modelos políticos-institucionais e jurídicosconstitucionais, com baixa densidade democrática, perpassa fronteiras, macula $\mathrm{o}$ Estado Nacional e corrompe a Soberania Política, pautando abalos e corrosões nos sistemas políticos que afetam o paradigma constitucional tanto a nível de sistemas internos, como na ordem internacional e supranacional. Ocorre, nas palavras de Ferrajoli (2005, p. ), "deformação das linhas tradicionais da democracia política e do Estado de Direito iniciada a partir da crise do Estado-Nação soberano, e sua localização através das fronteiras nacionais, resultante do processo de globalização de parcelas crescentes poder, tanto pública como privada."

$\mathrm{Na}$ Era das mundializações, porque são múltiplas, policêntricas e amórficas, as necessidades e pautas de reivindicações de cada país latino-americano se tornam estéreis das políticas de desenvolvimento econômico endógenas, para, progressivamente, agentes exógenos, notadamente por meio do Banco mundial, legitimados por poderes apolíticos e sob a chancela do desenvolvimentismo institucionalizado.

Esta dinâmica, própria do capitalismo de mercado, se aplica especialmente para os países em vias de desenvolvimento, como é o caso brasileiro e da América Latina, em sua totalidade. Em ensaio lançado originariamente em inglês, Plunder: when the rule of 
law is illegal, Mattei e Nader (2008, p. 12), desconstroem o termo rule of law, ao acentuar que o termo, de origem do common law fora concebido sem qualquer reivindicação democrática, e fundamente: "O Parlamento Inglês não era uma instituição democrática."

Acresça-se às ideias defendidas acerca da teoria dos transplantes legais, de sua vinculação ao conceito do rule of law, instrumento normativo da mundialização do capital e, nas palavras de Michael Hardt e Antonio Negri (2002), Niall Ferguson (2003), a dimensão de hegemonia como poder que combina força e consentimento por meio da persuasão. Negri defende a tese que a construção de consensos (o Consenso de Washington é emblemático neste sentido) suscita a incapacidade de determinação dos povos e Nações. É, por via de consequência, que a recepção ou adoção de padrões-tipo (standards) jurídico-normativos se faz premente.

\section{THE WORLD BANK LEGAL REVIEW, LAW AND DEVELOPMENT E O DESENVOLVIMENTISMO EXÓGENO}

"A fonte primordial do crescimento econômico é a estrutura institucional/organizacional de uma economia" (NORTH, 1997, p. 227). Com tal postulado, Douglas North consagrou o entendimento que fora força motriz de escola neoinstitucionalista e, por via de consequência, dos programas do Banco Mundial em políticas de desenvolvimento econômico da América latina, sobretudo no Brasil.

Com efeito, ao idealizar as estruturas Institucionais como motor propulsor do desenvolvimento econômico, foram vislumbradas possibilidades de arranjos jurídicos que alterassem o modelo desenvolvimentista - periférico e tardio, resultante da falência de um Estado providente ou welferista - e, como consequência, surge a necessidade premente das reformas de Estado.

Tais reformas seriam concebidas política, intelectual e financeiramente pelo Banco Mundial e outros atores internacionais, que, por meio de suas publicações, relatórios e estatísticas consagram e condicionam os modelos nacionais de desenvolvimento. São veiculados notadamente pelos The World Bank Legal Review (CISSÉ; THOMAS; WANG, 2013). As bases institucionais e arranjos jurídicos, que têm marco temporal dos anos 90 até a crise financeira global de 2008, e que foram balizadas por meio do Consenso de Washington. Tem como principais políticas públicas a disciplina fiscal, a liberalização financeira e comercial, total abertura da economia para investimentos, privatização, desregulamentação e proteção direta dos direitos de propriedade intelectual das multinacionais.

A questão que se coloca agora é a de estabelecer um repasse crítico acerca da escola law and development, bem como dos relátorios do Banco Mundial "The World Bank Report", no sentido de qualificá-los como recepção ou imposição ao modelo de desenvolvimento econômico consagrado pelo constitucionalismo latino-americano.

Para fundamentar tal análise, busca-se respaldo na doutrina de Nitschke (2015, p.866) que assevera que a realidade das transplantações jurídicas permeia a História da cultura jurídica latino-americana, notadamente a brasileira. E continua, "Na tradição luso-brasileira, desde a "Lei da Boa Razão" há combinação entre direito nacional e direito estrangeiro". Com efeito, a Lei da Boa Razão, de 18 de agosto de 1769 
permitia a resolução de "lacunas do ordenamento jurídico" concedendo a juízes recorrerem, conforme Cruz:

\begin{abstract}
"[P]rimitivos Principios", ao "Direito das Gentes" e ao "que se estabelece nas Leis Politicas, Economicas, Mercantís e Maritimas, que as mesmas Nações Christãs tem promulgado". Para este último caso, a Lei ia ainda mais longe: “(...) sendo muito mais racional, e muito mais coherente, que nestas interessantes materias se recorra antes em casos de necessidade ao subsidio proximo das sobreditas Leis das Nações Christãs, illuminadas, e polidas, que com ellas estão resplandecendo na boa, depurada, e sã jurisprudencia. (CRUZ, 1981, p. 124)
\end{abstract}

A absorção dos transplantes legais pelo ordenamento jurídico, que a época era colônia, portanto, reforça a prática reiterada do fenômeno de recepção, e, no que interessa mais especificamente ao presente estudo, concebe um entendimento histórico do binômio condicionado: desenvolvimento econômico-pacote institucional e jurídico.

No sítio do Banco Mundial, acerca da temática dos legal transplants e Cultura Jurídica, a instituição entende que muitos preceitos legais são muitas vezes inspirados por experiências estrangeiras. E, apesar dos acalorados debates acadêmicos, os transplantes legais são, não só possíveis como também são uma prática comum, necessária e imperativa para a busca plena do desenvolvimento.

Em trabalho acerca da "Cultura Jurídica e Reforma Judiciária" revela a importância da cultura legal para a reforma legal e a contextualização do desenvolvimento, embora incidindo sobre os problemas difíceis de definir, medir e fazer argumentos causais sobre o amplo e conceitualmente confuso fator "cultura jurídica."

$\mathrm{Na}$ ambiência global em que vivemos, onde uma multiciplicidade de ordens normativas que interagem e colidem, é muito comum as concepções que relacionam as reformas dos sistemas jurídicos com MODELOS-TIPO de desenvolvimento econômico. Há uma transplantação de paradigmas e arranjos jurídico-institucionais, com expertise e eficiência econômica, contextualizado social, jurídico, cultural e economicamente numa realidade de prosperidade institucional, para enxertá-los em outros contextos, temporalmente diferenciados, sem a prévia análise das adaptações necessárias à sua implantação. As trajetórias de instituições escolhidas para os projetos de crescimento e desenvolvimento "estão inseridas nos novos programas assistenciais voltados à disseminação e execução dos marcos jurídicos, ou o que se convencionou chamar de transplantes legais (legal transplants)"(GOMES NETO, 2012, p. 139).

Alvaro Santos (2006), no ensaio: The World Bank's Uses of the Rule of Law Promise in Economic Development, aponta - mesmo que refutando - a consagração da doutrina do "Estado de direito" (ou, com algo próximo do postulado da rule of law) como condicionante do discurso e prática de desenvolvimento. A ideia das regras da "Rule of Law", da Common Law, e de matriz liberal, deveriam ser o modelo crucial do sistema jurídico para o crescimento econômico. E mais: a previsibilidade, a exequibilidade e a eficácia do modelo jurídico seriam imprescindíveis para uma economia de mercado a florescer. Neste sentido, esclarece: 
O Direito está no centro do discurso e prática desenvolvimentistas atuais. A ideia de que o sistema jurídico é crucial para o crescimento econômico agora faz parte da sabedoria convencional na teoria do desenvolvimento. A expressão mais comum dessa ideia é o "Estado de Direito": uma ordem legal que consiste em regras previsíveis, exequíveis e eficientes que são exigidas para que uma economia de mercado floresça. O entusiasmo pela reforma do direito como estratégia de desenvolvimento cresceu durante os anos 90 e os recursos para a reforma dos sistemas jurídicos aumentaram em todos os lugares. (SANTOS, 2006, p. 253, tradução livre) ${ }^{4}$

A ideia do reformas jurídico-institucionais consagradas e disseminadas hegemonicamente pelo Banco Mundial, em países em via de desenvolvimento na América Latina - com realidades de dimensões históricas, sociais, culturais, econômicas, institucionais e jurídicas diferenciadas. Inúmeros estudiosos do movimento "Direito e Desenvolvimento" corroboram com tal entendimento. Para citar alguns, podemos mencionar: Trubek (2006), Mattei (2002), Garavito (2011), Gargarella (2014) e Santos (2006).

\section{CONCLUSÃo}

Com a realização do presente estudo, pretende-se elaborar um artigo científico que possam servir à solução da casuística que frequentemente se apresentar ao aos países latino-americanos e ao modelo de direito internacional econômico visto da América Latina, e que consagre uma matriz de desenvolvimento econômico constitucionalmente descolonial, de realidade do Ius Constitutionale Commune na América Latina (ICCAL), que consagre um modelo próprio para as idiossincrasias do continente latino-americano.

Entre o fluxo, a interação e o conflito de ordens jurídicas - nacionais, regionais, transnacionais e supranacionais - que seja consagrado um modelo de entendimento e aprendizagem do direito internacional compatível com as pluralidades locais e com um modelo e um processo de desenvolvimento que consagre a implementação de políticas públicas desenvolvimentistas endógenas, distributivas e de longo prazo;

A dimensão conceitual do fenômeno jurídico da transnacionalidade do direito, dos fluxos jurídicos e seja concebido sob um viés não imperialista e neocolonizador, pois apresenta enorme dificuldade para ciência jurídica tradicional pois conceber $\mathrm{o}$ fenômeno da transnacionalidade do direito frente a prescindibilidade estatal, vez que o Estado-nação habita o cerne doutrina do direito internacional;

\footnotetext{
${ }^{4}$ No original: Law is at the center of development discourse and practice today. The idea that the legal system is crucial for economic growth now forms part of the conventional wisdom in development theory. This idea's most common expression is the "rule of law" (ROL): a legal order consisting of predictable, enforceable and efficient rules required for a market economy to flourish. Enthusiasm for law reform as a development strategy boomed during the 1990s and resources for reforming legal systems soared everywhere.
} 
A internacionalização de modelos políticos-institucionais e jurídicosconstitucionais, com baixa densidade democrática, perpassa fronteiras, macula $\mathrm{o}$ Estado Nacional e corrompe a Soberania Política, pautando abalos e corrosões nos sistemas políticos que afetam o paradigma constitucional tanto a nível de sistemas internos, como na ordem internacional e supranacional.

A adoção de um "pacote de instituições corretas", transplantáveis de ambientes dotados de um bem-sucedido processo de desenvolvimento é uma estratégia que, todavia, nem sempre tem alcançado os resultados esperados, seja pela resistência política encontrada nos países para a realização das reformas institucionais, seja pela carência de efetividade de tais medidas - em muitos casos -, inconsistentes com a trajetória histórica vivenciada pelos arranjos nacionais.

A realidade acima pontuada, desvela evidente identidade existente entre rule of law, própria dos países de sistema jurídico vinculados ao Common Law e a matriz desenvolvimentista confeccionadas nas organização internacional de amparo ao desenvolvimento para os países periféricos.

Acresça-se que as ideias defendidas acerca da teoria dos transplantes legais, de sua vinculação ao conceito do rule of law, instrumento normativo da mundialização do capital e, nas palavras de Michael Hardt e Antonio Negri (2002), a dimensão de hegemonia como poder que combina força e consentimento por meio da persuasão.

A evidencia que as teses de que a construção de consensos (o Consenso de Washington é emblemático neste sentido) suscita a incapacidade de determinação dos povos e Nações. É, por via de consequência, que a recepção ou adoção de padrões-tipo (standart) jurídico-normativos de desenvolvimento econômico, veiculadas por cartilhas dos Banco Mundial, revelam ingerências e condicionantes desaconselháveis ao modelo institucional latino-americano.

As concepções da Escola "Direito e Desenvolvimento" adotada no contexto político-institucional latino-americano, consagra um modelo evidentemente desenvolvido por atores internacionais ativamente envolvidos, incompatíveis com a realidade institucional e constitucional regional de desenvolvimentismo descolonial.

\section{REFERÊNCIAS}

ARAÚJO, Sara. Desafiando a colonialidade. A ecologia de justiças como instrumento da descolonização jurídica. Hendu-Revista Latino-Americana de Direitos

Humanos, v. 6, n. 1, p. 26-46, 2015.

BRANCO, Luizella. Transnormatividade e cosmosmopolitismo jurídico: interfaces do direito administrativo global. Direito UNIFACS-Debate Virtual, n. 168, 2014. $<$ http://www.revistas.unifacs.br/index.php/redu/article/view/3163>. Acesso em 05 jun. 2017. 
CISSÉ, Hassane; MULLER, Sam; THOMAS, Chantal; WANG, Chenguang. 2013. The World Bank Legal Review, Volume 4: Legal Innovation and Empowerment for Development. World Bank Legal Review. Washington, DC: World Bank. Disponível em: <https://openknowledge.worldbank.org/handle/10986/12229>. Acesso em 05 jun. 2017.

CRUZ, Guilherme. O direito subsidiário na história do direito português. In: Obras Esparsas. Coimbra: Universidade de Coimbra, v. 2, parte 2, pp. 391-408, 1981.

FERGUSON, Niall. Empire: The Rise and Demise of the British World and the Lessons for Global Power. New York: Basic Books, 2003.

FERRAJOLI, Luigi. La crisis de la democracia en la era de la globalización. Anales de la cátedra Francisco Suárez, p. 37-67, 2005.

FRANKENBERG, Günther. A gramática da constituição e do direito. Trad. Elisete Antonuk. Belo Horizonte: Del Rey, 2007.

GARAVITO, César Rodríguez. El derecho en América Latina: un mapa para el pensamiento jurídico del siglo XXI. Buenos Aires: Siglo Veintiuno Editores, 2011.

GARGARELLA, Roberto. Explicando el constitucionalismo latinoamericano.

Rechtsgeschichte-Legal History, 2014.

GOMES NETO, José Mário Wanderley. Direito e desenvolvimento na perspectiva da consolidação do rule of law. Duc In Altum-Caderno de Direito, v. 3, n. 4, 2012.

HOLMES, Pablo. O Constitucionalismo entre a Fragmentação e a Privatização: Problemas Evolutivos do Direito e da Política na Era da Governança Global. Revista Dados, v. 57, n. 4, 2014.

MATTEI, Ugo. Efficiency in legal transplants: An essay in comparative law and economics. International Review of Law and Economics, v. 14, n. 1, p. 03-19, 1994.

MATTEI, Ugo. The Rise and Fall of Law and Economics: an Essay for Judge Guido Calabresi. Maryland Law Review, 2005. 
MATTEI, Ugo; NADER, Laura. Plunder: when the rule of law is illegal. John Wiley \& Sons, 2008.

LÓPEZ-MEDINA, Diego. El nacimiento del derecho comparado moderno como espacio geográfico y como disciplina: instrucciones básicas para su comprensión y uso desde américa latina. International Law: Revista Colombiana de Derecho Internacional, v. 13, n. 26, 2015.

MIGNOLO, Walter D. Novas reflexões sobre "Ideia da América Latina": a direita, a esquerda e a opção descolonial. Caderno CRH, v.21, n.53, p. 239-252, 2008.

NASCIMENTO, Valéria Ribas do; MARTINS, Evilhane Jum; IRIGARAY, Micheli Capuano. O Constitucionalismo latino-americano: desafios para uma maior aproximação brasileira através da lei n⿳o. 13.123/20151. Em Constituição, Economia e Desenvolvimento: Revista da Academia Brasileira de Direito Constitucional. Curitiba, 2016, vol. 8, n. 15, Jul.-Dez.

NEGRI, Antonio. Empire. Traduzido por Berilo Vargas. Rio de Janeiro. Editora Record, 2002.

NEVES, Marcelo. Transnacionalidade do direito: novas perspectivas dos conflitos entre ordens jurídicas. São Paulo: Quartier Latin, 2010.

NITSCHKE, Guilherme Carneiro Monteiro. Ativismo arbitral e lex mercatoria. Revista de Arbitragem e Mediação, São Paulo, v. 12, n. 44, p. 89-122, 2015.

NORTH, Douglass C. Some fundamental puzzles in economic history/development. In: ARTHUR, W. Brian; DURLAUF, Steven N.; LANE, David A. (orgs.). The economy as an evolving complex system II. MA: Addison-Wesley, 1997.

PEGORARO, Lucio. Constituciones (y reformas constitucionales)«impuestas» o «condicionadas». Para una reclasificación interdisciplinaria de la categoría.

Pensamiento Constitucional, v. 18, n. 18, p. 331-356, 2014.

SANTOS, Álvaro. The World Bank's Uses of the 'Rule of Law' Promise in Economic Development. In: SANTOS; A.; TRUBEK, D. (orgs.), The New Law and Economic 
Development: A Critical Appraisal. Cambridge: Cambridge University Press, p. 253300, 2006.

SILVA, Virgílio Afonso da. Colisões de direitos fundamentais entre ordem nacional e ordem transnacional. In: NEVES, Marcelo (org.). Em torno da transnacionalidade do direito: novas perspectivas dos conflitos entre ordens jurídicas. São Paulo: Quartier Latin, 2009.

TEUBNER, Gunther. Constitutional fragments. Oxford: Oxford University Press. 2012.

TEUBNER, Gunther. Global Bukowina: Legal pluralism in the world-society. In: TEUBNER, Gunther. GLOBAL LAW WITHOUT A STATE. Dartsmouth, p. 03-28, 1996.

TRUBEK, David. The 'Rule of Law'in Development Assistance: past, present, and future. The new law and economic development: A critical appraisal, v. 74, 2006.

VON BOGDANDY, Armin. Ius Constitutionale Commune in Latin America: A look at a transformative constitutionalism. Revista Derecho del Estado, n. 34, p. 3-50, 2015.

WATSON, Alan. Legal transplants: an approach to comparative law. University of Georgia Press, 1993. 